M.S. Robbins, MD

B.M. Grosberg, MD

U. Napchan, MD

S.C. Crystal, MD

R.B. Lipton, MD

Address correspondence and reprint requests to Dr. Matthew S. Robbins, The Montefiore Headache Center, 1575 Blondell Avenue, Suite 225, Bronx, NY 10461

marobbin@montefiore.org

\title{
Clinical and prognostic subforms of new daily-persistent headache
}

Pit

\section{ABSTRACT}

Background: According to the International Classification of Headache Disorders (ICHD)-2, primary daily headaches unremitting from onset are classified as new daily-persistent headache $(\mathrm{NDPH})$ only if migraine features are absent. When migraine features are present, classification is problematic.

Methods: We developed a revised NDPH definition not excluding migraine features (NDPH-R), and applied it to consecutive patients seen at the Montefiore Headache Center. We divided this group into patients meeting ICHD-2 criteria (NDPH-ICHD) and those with too many migraine features for ICHD-2 (NDPH-mf). We compared clinical and demographic features in these groups, identifying 3 prognostic subgroups: persisting, remitting, and relapsing-remitting. Remitting and relapsingremitting patients were combined into a nonpersisting group.

Results: Of 71 NDPH-R patients, 31 (43.7\%) also met NDPH-ICHD-2 criteria. The NDPH-mf and the NDPH-ICHD-2 groups were similar in most clinical features though the NDPH-mf group was younger, included more women, and had a higher frequency of depression. The groups were similar in the prevalence of allodynia, triptan responsiveness, and prognosis. NDPH-R prognostic subforms were also very similar, although the persisting subform was more likely to be of white race, to have anxiety or depression, and to have a younger onset age.

Conclusions: Current International Classification of Headache Disorders (ICHD)-2 criteria exclude the majority of patients with primary headache unremitting from onset. The proposed criteria for revised new daily-persistent headache definition not excluding migraine features (NDPH-R) classify these patients into a relatively homogeneous group based on demographics, clinical features, and prognosis. Both new daily-persistent headache with too many migraine features for ICHD-2 and new daily-persistent headache meeting ICHD-2 criteria include patients in equal proportions that fall into the persisting, remitting, and relapsing-remitting subgroups. Our criteria for NDPH-R should be considered for inclusion in ICHD-3. Neurology ${ }^{\circledR}$ 2010;74:1358-1364

\section{GLOSSARY}

ASC = allodynia symptom checklist $\mathbf{C D H}=$ chronic daily headache; $\mathbf{C T T H}=$ chronic tension-type headache; $\mathbf{E T T H}=\mathrm{epi}-$ sodic tension-type headache; ICHD = International Classification of Headache Disorders; NDPH = new daily-persistent headache; NDPH-ICHD = new daily-persistent headache meeting International Classification of Headache Disorders-2 criteria; NDPH-mf = new daily-persistent headache with too many migraine features for International Classification of Headache Disorders-2; NDPH-R = revised new daily-persistent headache definition not excluding migraine features; PHQ-9 = Patient Health Questionnaire; $\mathbf{S I H}=$ spontaneous intracranial hypotension

Headache is the leading reason for outpatient visits to neurologists, ${ }^{1}$ and patients with chronic daily headache $(\mathrm{CDH})$ are particularly challenging. There are 4 types of long-duration $\mathrm{CDH}$ : chronic migraine, chronic tension-type headache (CTTH), hemicrania continua, and new daily-persistent headache (NDPH). The 1-year population prevalence of NDPH has been reported to be $0.03 \%{ }^{2}$ to $0.1 \%{ }^{3}$ It may be more common in adolescents than adults, ${ }^{4}$ and in children and adolescents is more common than CTTH. ${ }^{5} \mathrm{NDPH}$ distinguishes itself from the other types of $\mathrm{CDH}$ by its signature feature of continuous or near-continuous head pain from onset. Originally described by Vanast in

Supplemental data at www.neurology.org

From The Montefiore Headache Center (M.S.R., B.M.G., U.N., S.C.C., R.B.L.), Saul R. Korey Department of Neurology, and Department of Epidemiology and Population Health (R.B.L.), Albert Einstein College of Medicine, Bronx, NY.

Disclosure: Author disclosures are provided at the end of the article.

Presented in part in abstract form at the 14th International Headache Congress, September 10-13, 2009, Philadelphia, PA. 
Table 1 International Classification of Headache Disorders, 2nd edition criteria for new daily-persistent headache ${ }^{9}$

A. Headache for more than 3 months fulfilling criteria $B-D^{a}$

B. Headache is daily and unremitting from onset or less than 3 days from onset

C. At least 2 of the following pain characteristics:

1. Bilateral location

2. Pressing/tightening (nonpulsating) quality

3. Mild or moderate intensity

4. Not aggravated by routine physical activity such as walking or climbing stairs

D. Both of the following:

1. No more than one of photophobia, phonophobia, or mild nausea

2. Neither moderate or severe nausea or vomiting

E. Not attributed to another disorder

aThe revised criteria for new daily-persistent headache ${ }^{5}$ do not require $\mathrm{C}$ or $\mathrm{D}$.

$1986,{ }^{6}$ some of his patients had migraine features, and the majority of his patients achieved complete headache resolution within a 2-year time period.

Subsequent case series have shown that NDPH can persist for years, often becoming refractory to treatment. ${ }^{7}$ Operational diagnostic criteria for NDPH were proposed in $1994^{8}$ but the condition was not included in the International Classification of Headache Disorders until 2004 (ICHD-2). ${ }^{9}$ The ICHD-2 criteria, unlike the predecessor criteria, exclude patients who have prominent migraine features (table 1). In published case series, migraine features such as throbbing pain, nausea, vomiting, photophobia, and phonophobia are common. ${ }^{5,10,11}$ Several series have used the original Silberstein-Lipton criteria, which only require an average of 15 or more days of monthly headache, 8 or modified ICHD-2 criteria (table 1). ${ }^{5}$ The ICHD-2 criteria for NDPH are problematic as patients with otherwise typical NDPH are not easily classified in the presence of migraine features.

Accordingly, we studied a group of patients with primary headaches that were daily from onset using criteria for NDPH that do not exclude migraine features (NDPH-R). The objective of this study was to gain a greater understanding of the clinical features and prognosis of patients presenting with $\mathrm{CDH}$ from headache onset. We examined a large series of consecutive patients presenting with NDPH to our headache center, and compared patients fulfilling ICHD-2 criteria to patients with migraine features, based on epidemiologic profiles, clinical features, treatment responsiveness, and prognosis to test the hypothesis that the groups were similar.

METHODS This study was conducted as a retrospective chart review of patients seen at the Montefiore Headache Center from September 2005 to April 2009. All patients were over 12 years of age, although their headache onset may have preceded age 12 . All new patients completed a standardized questionnaire that captures detailed demographic, headache, past medical, social, and family history characteristics [http://www.montefiore.org/ documents / MHC\%20New\%20Patient\%20Questionnaire\%20 (with\%20allodynia\%20-\%205-6-08).doc]. As the questionnaire was updated in 2008, the allodynia symptom checklist (ASC), a validated questionnaire for the presence of allodynia, was included, ${ }^{12}$ as was the Patient Health Questionnaire (PHQ-9), a validated sensitive and specific screen for major depression. ${ }^{13}$ An ASC score $>2$ may indicate at least mild allodynia, and a PHQ-9 score $>4$ may indicate mild depression. The majority of patients were seen and examined by both a headache medicine fellow and faculty member, and further investigational studies such as neuroimaging, blood tests, and lumbar puncture were requested as clinically indicated to exclude secondary etiologies.

$\mathrm{NDPH}$ was diagnosed according to the revised ICHD- 2 criteria used recently by Kung et al. ${ }^{5}$ We designated these patients as NDPH-R. Patients fulfilling NDPH-R but not the ICHD-2 criteria (because of migraine features) were designated NDPH$\mathrm{mf}$, and patients fulfilling ICHD-2 criteria were designated NDPH-ICHD. All other headache diagnoses were made using the ICHD-2 criteria. Medication overuse was defined as the level of medication intake needed for the diagnosis of medicationoveruse headache. ${ }^{2}$ Management decisions were made at the discretion of the treating physicians.

If patients had a history of episodic migraine or episodic tension-type headache (ETTH), they could only be diagnosed with NDPH-R if they had a low baseline headache frequency (less than 4 days of headache monthly) and no clear escalation of headache frequency prior to NDPH-R onset. Patients with other forms of CDH (chronic migraine, CTTH, and hemicrania continua) or clinically suspected of secondary headache disorders, such as post-traumatic headache, spontaneous intracranial hypotension (SIH), and idiopathic intracranial hypertension, were excluded.

We further categorized NDPH-R into 3 temporal profiles: 1) a persisting form with continuous headache from the onset, 2) a remitting form with either a complete remission of the continuous headache or with residual headache occurring less than 5 days per month for at least 3 months, and 3) a relapsingremitting form, defined by periods of continuous headache interspersed with pain-free periods. NDPH-R duration was defined as the time period between headache onset and first visit at our center.

Patient subgroup proportions were compared using a 2-tailed Fisher exact test. Statistical significance was defined as a $p$ value less than or equal to 0.05 . This study was approved by Montefiore Medical Center's Institutional Review Board. Written informed consent from patients was not obtained based on the retrospective study design. 
Table 2 Demographics, circumstances of onset, prior headache history, family history, and psychiatric comorbidities of NDPH-R, NDPHICHD, and NDPH-mf

\begin{tabular}{|c|c|c|c|c|}
\hline Feature & $\begin{array}{l}\text { NDPH-R, } \\
\mathrm{n}(\%)\end{array}$ & $\begin{array}{l}\text { NDPH-ICHD, } \\
\text { n (\%) }\end{array}$ & $\begin{array}{l}\text { NDPH-mf, } \\
\mathrm{n}(\%)\end{array}$ & $p$ Value \\
\hline No. & 71 & $31(43.7)$ & 40 (56.3) & - \\
\hline Female & $51(71.8)$ & $18(58.1)$ & 33 (82.5) & $0.033^{\mathrm{a}}$ \\
\hline White & $57(80.3)$ & 26 (83.9) & 31 (77.5) & 0.56 \\
\hline Black & $4(5.6)$ & $2(6.5)$ & $2(5.0)$ & 1.0 \\
\hline Hispanic & $7(9.9)$ & $3(9.7)$ & $4(10.0)$ & 1.0 \\
\hline Onset age $<10 y$ & $2(2.8)$ & $0(0.0)$ & $2(5.0)$ & 0.50 \\
\hline Onset age $10-19 y$ & $15(21.1)$ & $3(9.7)$ & 12 (30.0) & 0.14 \\
\hline Onset age $20-29 y$ & $22(40.0)$ & 10 (32.3) & $12(30.0)$ & 0.45 \\
\hline Onset age $30-39$ y & $12(16.9)$ & $6(19.4)$ & $6(15.0)$ & 0.75 \\
\hline Onset age $40-49 y$ & $12(16.9)$ & $7(22.6)$ & $5(12.5)$ & 0.34 \\
\hline Onset age $>49 y$ & $8(11.3)$ & $5(16.1)$ & $3(7.5)$ & 0.28 \\
\hline Recalling specific onset day & $30(42.3)$ & $14(45.2)$ & $16(40.0)$ & 0.81 \\
\hline Recalling specific onset day or month & $59(83.1)$ & 30 (96.8) & 29 (72.5) & $0.0090^{\circ}$ \\
\hline Recalling triggering event & $33(46.5)$ & 13 (41.9) & $20(50.0)$ & 0.63 \\
\hline Preexisting episodic migraine history & $13(18.3)$ & $5(16.1)$ & $8(20.0)$ & 0.76 \\
\hline Preexisting episodic TTH history & $5(7.0)$ & 4 (12.9) & $1(2.5)$ & 0.16 \\
\hline $\begin{array}{l}\text { Preexisting episodic migraine } \\
\text { or TTH history }\end{array}$ & $18(25.4)$ & $9(29.0)$ & $9(22.5)$ & 0.59 \\
\hline Self-reported history of anxiety disorder & 24 (33.8) & $7(22.6)$ & $17(42.5)$ & 0.12 \\
\hline Self-reported history of depression & 25 (35.2) & $6(19.4)$ & $19(47.5)$ & $0.023^{\mathrm{a}}$ \\
\hline $\begin{array}{l}\text { Self-reported history of anxiety } \\
\text { or depression }\end{array}$ & $36(50.7)$ & 11 (35.5) & 25 (62.5) & $0.032^{\mathrm{a}}$ \\
\hline PHQ-9 >4 & $23(62.2)$ & $9(50.0)$ & 14 (73.7) & 0.18 \\
\hline $\begin{array}{l}\text { First-degree relative with frequent } \\
\text { headache }\end{array}$ & 35 (49.3) & $17(54.8)$ & $18(45.0)$ & 0.47 \\
\hline
\end{tabular}

Abbreviations: NDPH-ICHD = new daily-persistent headache meeting International Classification of Headache Disorders-2 criteria; NDPH-mf = new daily-persistent headache with too many migraine features for International Classification of Headache Disorders-2; $\mathrm{NDPH}-\mathrm{R}=$ revised new daily-persistent headache definition not excluding migraine features; PHQ-9 = Patient Health Questionnaire; TTH = tension-type headache. aSignificant. groups in their prior history of episodic headaches overall, ETTH, or migraine. Only one patient had a history of episodic migraine with aura, and she was in the NDPH-ICHD group.

Family headache history. Nearly half (49.3\%) of NDPH-R patients reported a family history of frequent headaches. There were no significant differences in family history between NDPH-ICHD patients (54.8\%) and NDPH-mf patients (45.0\%).

Medical and psychiatric comorbidities. Medical comorbidities were reported in 28 patients (39.4\%). The most common condition reported was hyperlipidemia $(\mathrm{n}=12,16.9 \%)$, followed by hypertension $(n=9,12.7 \%)$, asthma $(n=6,8.5 \%)$, and diabetes $(\mathrm{n}=4,5.6 \%)$. Polycystic ovarian syndrome, irritable bowel syndrome, treated hypothyroidism, restless legs syndrome, and obstructive sleep apnea each occurred in 3 patients (4.2\%), and 2 patients had fibromyalgia (2.8\%).

A preexisting history of psychiatric disorders was significantly more common in NDPH-mf than in NDPH-ICHD for depression ( $47.5 \%$ vs $19.4 \%, p=$ $0.02)$ but not anxiety ( $42.5 \%$ vs $22.6 \%, p=0.13)$. PHQ-9 scores were collected in 18 NDPH-ICHD patients and $19 \mathrm{NDPH}$-mf patients. The proportion of patients exceeding a cut score of 4 did not differ between the groups $(73.7 \%$ vs $50 \%, p=0.18)$.

Onset. Onset age ranged from 8 to 76 years, with a median age of 28 years overall, 26 years in women, and 28 years in men (figure e-1 on the Neurology ${ }^{\circledR}$ Web site at www.neurology.org). The median onset age was slightly older in NDPH-ICHD (overall: 34 years, women: 34 years, men: 33 years) than in NDPH-mf (overall: 25 years, women: 25 years, men: 21 years). September was the most common month of onset overall and in both subgroups, and a second peak was noted in March for NDPH-R and NDPHICHD (figure e-2). Overall, $46.5 \%$ recalled a specific trigger, without significant differences between NDPH-ICHD (41.9\%) and NDPH-mf (50.0\%). The most common NDPH-R trigger was a preceding flu-like or upper respiratory illness $(\mathrm{n}=10$, $14.1 \%)$, followed by a stressful life event $(\mathrm{n}=7$, $9.9 \%)$ and menarche $(\mathrm{n}=3,4.2 \%)$. Two patients reported headache onset while selective serotonin reuptake inhibitors (citalopram, sertraline) given for depression were being tapered. One patient experienced symptom onset 2 days after her second vaccination for human papillomavirus.

Clinical features. Table 2 displays the clinical features. NDPH-mf patients were more likely to have throbbing pain, nausea, vomiting, photophobia, phonophobia, and aggravation by physical activity. 


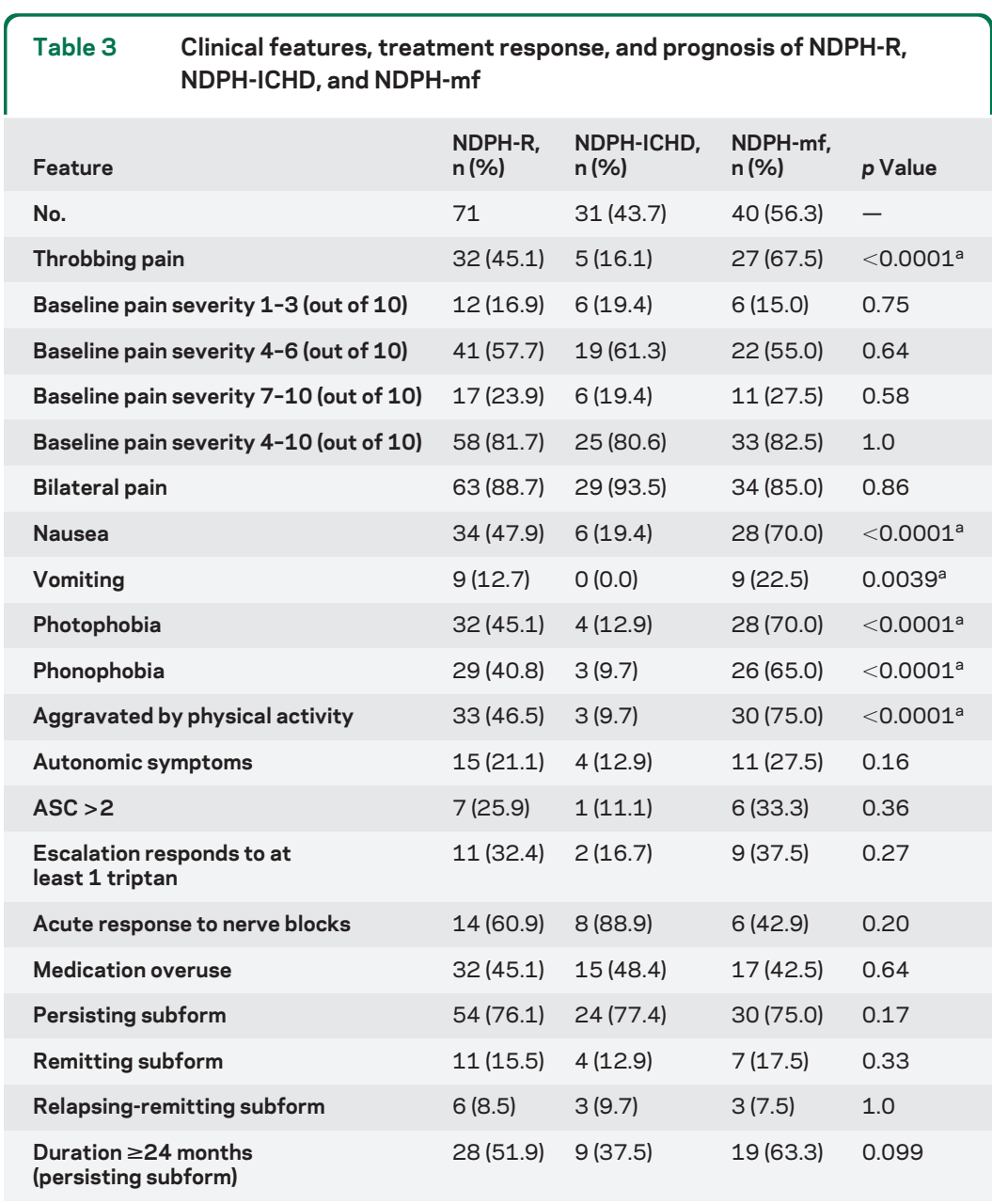

Abbreviations: ASC = allodynia symptom checklist ${ }^{12}$; NDPH-ICHD = new daily-persistent headache meeting International Classification of Headache Disorders-2 criteria; NDPH$\mathrm{mf}=$ new daily-persistent headache with too many migraine features for International Classification of Headache Disorders-2; NDPH-R = revised new daily-persistent headache definition not excluding migraine features.

aSignificant.
2.11. However, although ASC $>2$ was more common in NDPH-mf (33.3\% vs $11.1 \%)$, this was not significant.

Imaging. All patients underwent neuroimaging. Sixty-eight patients (95.8\%) had a brain MRI, and the remaining 3 patients had a noncontrast head CT scan. Thirty-five patients $(49.3 \%)$ had contrastenhanced MRI scans as well. MRI abnormalities were scarce, occurring in 5 NDPH-ICHD and 6 $\mathrm{NDPH}$-mf patients. Abnormalities included 5 patients with punctate white matter lesions, 2 patients with white matter ischemic changes, 2 patients with $1-\mathrm{cm}$ pineal cysts, 1 patient with 2 small venous angiomas, and 1 patient with a 1.0 - by $0.6-\mathrm{cm}$ right frontal arachnoid cyst. Sixteen patients $(22.5 \%)$ had lumbar punctures, all of which were normal (including opening pressure) except a slightly elevated protein level of $44 \mathrm{mg} / \mathrm{dL}$ in 1 patient.

Treatment. Thirty-four NDPH-R, 12 NDPHICHD, and $22 \mathrm{NDPH}-\mathrm{mf}$ patients tried at least 1 triptan for headache escalations. NDPH-mf patients were more likely to report some improvement in pain $(37.5 \%$ vs $16.7 \%)$, but this did not reach significance. In some patients nerve blocks with $0.5 \%$ bupivacaine were performed in areas tailored to the location of the patient's pain, and included greater occipital, lesser occipital, auriculotemporal, supraorbital, and supratrochlear nerve blockade. Twentythree NDPH-R patients had nerve blocks ( 9 in NDPH-ICHD, 14 in NDPH-mf). NDPH-ICHD patients were more likely to report a significant decrease in pain severity for at least 1 day as compared with NDPH-mf patients ( $88.9 \%$ vs $42.9 \%$ ), but this difference was also not significant. Medication overuse occurred in $45.1 \%$ overall, and was similar in NDPH-ICHD (48.4\%) and NDPH-mf (42.5\%). Ten of the 11 patients (90.9\%) with the remitting subform were on preventive medications when their continuous headache pattern broke, the most frequent of which were nortriptyline $(n=6)$ and topiramate $(n=4)$. No patient in the relapsingremitting subform was taking preventive medications at the time when the continuous headache pattern broke for the first time.

Prognosis. Overall, $76.1 \%$ of NDPH-R had the persisting subform, with similar proportions in NDPHICHD (77.4\%) and NDPH-mf (75.0\%). The relative frequencies of the remitting subform were similar for NDPH-ICHD (12.9\%) and NDPH-mf $(17.5 \%)$ and for the relapsing-remitting subform $(9.7 \%, 7.5 \%)$. The median duration of the persisting subform was longer in NDPH-mf (31 months) than in NDPH-ICHD (18 months). A higher proportion of NDPH-mf had headache duration of 24 months 
or longer $(63.3 \%$ vs $37.5 \%)$, but this was not significant. Of the 11 patients with the remitting subform, the time to remission ranged from 4 months to 54 years, with a median duration of 21 months. Of the 6 patients who had the relapsing-remitting subform, the time to first remission ranged from 3 to 24 months, with a median duration of 5.5 months.

Comparison of NDPH-R prognostic subtypes. NDPH-R patients were grouped by prognostic subforms. As there were far fewer patients in the remitting $(n=11)$ and the relapsing-remitting $(n=6)$ subforms than in the persisting $(\mathrm{n}=54)$ subforms, the remitting and the relapsing-remitting subgroups were combined, labeled as the nonpersisting subform.

Demographics, prior headache history, family history, psychiatric comorbidity, and onset. As shown in table 4 , the prognostic subforms of NDPH-R are largely

\begin{tabular}{|c|c|c|c|c|c|}
\hline $\begin{array}{l}\text { Demographic } \\
\text { comorbidity, }\end{array}$ & $\begin{array}{l}\text { s, prior heac } \\
\text { and onset in }\end{array}$ & $\begin{array}{l}\text { lache histo } \\
\text { relation to }\end{array}$ & $\begin{array}{l}\text { y, family hist } \\
\text { NDPH-R prog }\end{array}$ & $\begin{array}{l}\text { tory, psychia } \\
\text { gnostic subt }\end{array}$ & $\begin{array}{l}\text { atric } \\
\text { types }\end{array}$ \\
\hline Feature & $\begin{array}{l}\text { Remitting, } \\
\mathrm{n}(\%)\end{array}$ & $\begin{array}{l}\text { Relapsing- } \\
\text { remitting, } \\
\mathrm{n}(\%)\end{array}$ & $\begin{array}{l}\text { Remitting + } \\
\text { relapsing- } \\
\text { remitting, } \\
\mathrm{n}(\%)\end{array}$ & $\begin{array}{l}\text { Persisting, } \\
\mathrm{n}(\%)\end{array}$ & $p$ Value \\
\hline No. & 11 & 6 & 17 & 54 & - \\
\hline Female & 9 (81.8) & 5 (83.3) & 14 (82.4) & 37 (68.5) & 0.36 \\
\hline White & $7(63.6)$ & $3(50.0)$ & $10(58.8)$ & $47(87.0)$ & $0.031^{a}$ \\
\hline Black & 2 (18.2) & $1(16.7)$ & $3(17.6)$ & $1(1.9)$ & $0.040^{\mathrm{a}}$ \\
\hline Hispanic & 2 (18.2) & 2 (33.3) & 4 (23.5) & $3(5.6)$ & 0.052 \\
\hline Onset age $<10 y$ & 1 (9.1) & $0(0.0)$ & $1(5.9)$ & $1(1.9)$ & 0.42 \\
\hline Onset age $10-19 y$ & 2 (18.2) & $1(16.7)$ & $3(17.6)$ & 12 (22.2) & 1.0 \\
\hline Onset age $20-29 y$ & 2 (18.2) & $0(0.0)$ & $2(11.8)$ & $20(37.0)$ & 0.071 \\
\hline Onset age $30-39 y$ & 2 (18.2) & $4(66.7)$ & 6 (35.3) & $6(11.1)$ & $0.030^{a}$ \\
\hline Onset age $40-49 y$ & $1(9.1)$ & $1(16.7)$ & $2(11.8)$ & 10 (18.5) & 0.72 \\
\hline Onset age $>49 y$ & $3(27.3)$ & $0(0.0)$ & $3(17.6)$ & $5(9.3)$ & 0.39 \\
\hline Recalls onset day & $6(54.5)$ & $3(50.0)$ & $9(52.9)$ & 21 (38.9) & 0.40 \\
\hline Recalls onset day or month & $8(72.7)$ & $3(50.0)$ & $11(64.7)$ & 45 (83.3) & 0.17 \\
\hline Recalling triggering event & $6(54.5)$ & 2 (33.3) & $8(47.1)$ & 25 (46.3) & 1.0 \\
\hline Preexisting migraine & $3(27.3)$ & 2 (33.3) & $5(29.4)$ & $7(13.0)$ & 0.14 \\
\hline Preexisting ETTH & $0(0.0)$ & $1(16.7)$ & $1(5.9)$ & $4(7.4)$ & 1.0 \\
\hline Preexisting migraine or ETTH & $3(27.3)$ & $3(50.0)$ & 6 (35.3) & $11(20.4)$ & 0.17 \\
\hline Self-reported anxiety & $3(27.3)$ & $0(0.0)$ & $3(17.6)$ & 21 (38.9) & 0.15 \\
\hline Self-reported depression & $3(27.3)$ & $0(0.0)$ & $3(17.6)$ & $22(40.7)$ & 0.14 \\
\hline $\begin{array}{l}\text { Self-reported anxiety or } \\
\text { depression }\end{array}$ & $5(45.5)$ & $0(0.0)$ & $5(29.4)$ & $31(57.4)$ & $0.0059^{a}$ \\
\hline PHQ-9 >4 & $2(50.0)$ & 1 (33.3) & $3(42.9)$ & $20(66.7)$ & 0.39 \\
\hline $\begin{array}{l}\text { First-degree relative with } \\
\text { frequent headache }\end{array}$ & $6(54.5)$ & $3(50.0)$ & $9(52.9)$ & 25 (46.3) & 0.78 \\
\hline
\end{tabular}

Abbreviations: ETTH = episodic tension-type headache; NDPH-ICHD = new daily-persistent headache meeting International Classification of Headache Disorders-2 criteria; NDPH-mf = new daily-persistent headache with too many migraine features for International Classification of Headache Disorders-2; NDPH-R = revised new daily-persistent headache definition not excluding migraine features; $\mathrm{PHQ}-9=$ Patient Health Questionnaire.

asignificant. similar in most respects, except that patients in the persisting subform were more likely to be of white race and have a history of anxiety or depression. The median onset was older in the nonpersisting subform overall ( 34 vs 26 years), for women (34 vs 24 years), but not for men, where it was older in the persisting subform (28 vs 16 years). Patients with the nonpersisting subform were more likely to be of black race, and have a headache onset from age 30 to $39(35.3 \%$ vs $11.1 \%)$.

Headache features and treatment aspects. Headache features and treatment aspects are shown in table 5. There were no significant differences among the persisting and nonpersisting subforms in any of the ascertained headache features or treatment aspects. In addition, there were no differences among the prognostic subforms in terms of fulfilling ICHD-2 criteria for NDPH ( $41.2 \%$ of nonpersisting vs $44.4 \%$ of persisting subforms).

DISCUSSION In this study, we examined a large series of patients meeting NDPH-R criteria.

We found that the majority of these patients do not fulfill NDPH-ICHD-2 criteria, but do meet criteria for NDPH-mf. Other groups applying comparable criteria have drawn similar conclusions. ${ }^{14}$ One possibility is that the ICHD-2 criteria are too restrictive and that the group with migraine features is part of the NDPH spectrum. Another possibility is that the NDPH-R criteria are too loose and we are expanding this rubric beyond its clinical utility. In the current classification, some patients who meet $\mathrm{NDPH}$-mf criteria (those with a history of $\geq 5$ prior attacks of migraine without aura) would be classified as chronic migraine, ${ }^{15}$ though they had no history of escalation of headache frequency prior to NDPH onset. NDPH-mf patients without a history of $\geq 5$ prior attacks of migraine without aura would not be classifiable.

We compared the demographic, clinical, and prognostic features of these 2 groups and found that they were substantially similar, particularly in outcome. NDPH-ICHD patients were more likely to recall the onset day or month, and NDPH-mf patients were more likely to be women, have a history of depression or anxiety, and by definition, migraine features. The female predominance and increased comorbidity of depression and anxiety may reflect a stronger biologic connection between NDPH-mf and migraine.

When comparing NDPH patients by their prognostic subforms, there were strikingly few differences among the nonpersisting and persisting groups. The persisting form was present in $77.4 \%$ of the NDPHICHD-2 and $75.0 \%$ of the NDPH-mf groups. The 
Table 5 Headache features and treatment response in prognostic subtypes

\begin{tabular}{|c|c|c|c|c|c|}
\hline Feature & $\begin{array}{l}\text { Remitting, } \\
\mathrm{n}(\%)\end{array}$ & $\begin{array}{l}\text { Relapsing- } \\
\text { remitting, } \\
\text { n (\%) }\end{array}$ & $\begin{array}{l}\text { Remitting + } \\
\text { relapsing- } \\
\text { remitting, } \\
\mathrm{n}(\%)\end{array}$ & $\begin{array}{l}\text { Persisting, } \\
\text { n (\%) }\end{array}$ & $p$ Value \\
\hline Throbbing pain & $4(36.4)$ & $3(50.0)$ & $7(41.2)$ & 25 (46.3) & 0.78 \\
\hline Baseline pain severity $1-3$ & $3(27.3)$ & $1(16.7)$ & $4(23.5)$ & $8(14.8)$ & 0.46 \\
\hline Baseline pain severity 4-6 & $7(63.6)$ & $4(66.7)$ & $11(64.7)$ & $30(55.6)$ & 0.58 \\
\hline Baseline pain severity 7-10 & $1(9.1)$ & $1(16.7)$ & $2(11.8)$ & $15(27.8)$ & 0.21 \\
\hline Baseline pain severity 4-10 & $8(72.7)$ & 5 (83.3) & $13(76.5)$ & 45 (83.3) & 0.50 \\
\hline Bilateral pain & $10(90.9)$ & $6(100)$ & $16(94.1)$ & 47 (87.0) & 0.67 \\
\hline Nausea & $5(45.5)$ & $1(16.7)$ & $6(35.3)$ & $29(53.7)$ & 0.27 \\
\hline Vomiting & $1(9.1)$ & $0(0.0)$ & $1(5.9)$ & $8(14.8)$ & 0.68 \\
\hline Photophobia & $5(45.5)$ & $3(50.0)$ & $8(47.1)$ & $24(44.4)$ & 1.0 \\
\hline Phonophobia & $6(54.5)$ & $3(50.0)$ & $9(52.9)$ & 20 (37.0) & 0.27 \\
\hline $\begin{array}{l}\text { Aggravated by physical } \\
\text { activity }\end{array}$ & $6(54.5)$ & $3(50.0)$ & $9(52.9)$ & $24(44.4)$ & 0.59 \\
\hline Autonomic symptoms & $2(18.2)$ & $1(16.7)$ & $3(17.6)$ & 12 (22.2) & 1.0 \\
\hline ASC $>2$ & $2(50.0)$ & $1(100)$ & $3(60.0)$ & 4 (18.2) & 0.091 \\
\hline $\begin{array}{l}\text { Escalation responds to at } \\
\text { least } 1 \text { triptan }\end{array}$ & $1(9.1)$ & $2(50.0)$ & $3(42.9)$ & $8(25.8)$ & 0.39 \\
\hline Medication overuse & $9(81.8)$ & $1(16.7)$ & $10(58.8)$ & $22(40.7)$ & 0.27 \\
\hline $\begin{array}{l}\text { Acute response to nerve } \\
\text { blocks }\end{array}$ & $0(0.0)$ & $1(100)$ & $1(100)$ & $12(54.5)$ & 1.0 \\
\hline Fulfills ICHD-2 criteria & $4(36.4)$ & $3(50.0)$ & $7(41.2)$ & $24(44.4)$ & 1.0 \\
\hline
\end{tabular}

Abbreviations: ASC = allodynia symptom checklist ${ }^{12} ; \mathrm{ICHD}=$ International Classification of Headache Disorders; NDPH-ICHD = new daily-persistent headache meeting International Classification of Headache Disorders-2 criteria; NDPH-mf = new daily-persistent headache with too many migraine features for International Classification of Headache Disorders-2; NDPH-R = revised new daily-persistent headache definition not excluding migraine features.

asignificant.
Epstein-Barr virus ${ }^{17}$ or other infections. ${ }^{11}$ Our finding that NDPH patients can have their headache onset in a biphasic pattern during the beginning of spring and autumn could also impart a seasonal trigger, such as an infection, as a common inciting factor. However, though NDPH patients may have elevated CSF levels of a proinflammatory cytokine, tumor necrosis factor- $\alpha$, this does not seem related to having a history of an antecedent infection. ${ }^{18}$

Other potential etiologies include stressful life events, cervical joint hypermobility, ${ }^{19}$ and defective internal jugular venous drainage. ${ }^{20}$ In addition, SIH is an important secondary disorder to exclude, ${ }^{21}$ as it can present as NDPH without orthostatic symptoms, ${ }^{22}$ often goes undiagnosed, and may result in a long delay of effective treatment..$^{23}$ Although we cannot definitively exclude $\mathrm{SIH}$ in all our patients, nearly half had gadolinium-enhanced MRI examinations and one quarter had lumbar punctures that showed no evidence of this disorder. Finally, Mack ${ }^{16}$ reported that chronic migraine can have an abrupt onset in $30 \%$ of children with a prior history of episodic migraine, and often had similar triggers, which was quite similar to NDPH.

Our series also reports new aspects to NDPH that have not been highlighted previously. We report an association of declining selective serotonin reuptake inhibitor dose in 2 patients, possibly reflecting an underlying dysfunctional serotonergic pathway. In addition, we found aura symptoms to be rare, where only one patient had a preexisting history of episodic migraine with aura, and a second patient had aura symptoms with painful exacerbations after NDPH onset. Taken together, this $2.8 \%$ of our NDPH patients with aura is far lower than the $30 \%$ of patients with migraine ${ }^{24}$ and the $5 \%$ of the adult population ${ }^{25}$ reported to have aura.

Another novel feature that we report includes episodes of bilateral facial flushing in some patients, which could be an associated autonomic or vasomotor symptom. In addition, some patients with NDPH may be triptan-responsive, and although this did not reach significance, NDPH patients with a migraine headache phenotype were more responsive than the group with a TTH phenotype.

Our study has many limitations. Our findings may not be applicable to the general population, as this case series only included patients seen at a single tertiary headache center, and did not include young children. Patients having a form of NDPH that either remits shortly after 3 months or causes little disability may not seek medical attention at all, or at least be less likely to be referred to a neurologist or headache center. Self-reported family histories and psychiatric comorbidities may not be accurate. Fi- 
nally, as this is a retrospective case series, recall bias is inevitable, although most patients recalled the circumstances of onset rather easily, even though some could not report the specific date of onset.

\section{AUTHOR CONTRIBUTIONS}

Statistical analysis was conducted by Dr. Matthew S. Robbins.

\section{DISCLOSURE}

Dr. Robbins reports no disclosures. Dr. Grosberg serves on a scientific advisory board for Kowa Pharmaceuticals America, Inc.; has received honoraria for speaking engagements or educational activities from Merck Serono and GlaxoSmithKline; and received institutional research support from Allergan, Inc., Merck Serono, GlaxoSmithKline, Endo Pharmaceuticals, Boston Scientific, Neuralieve Inc., Advanced Bionics, ProEthics, Minster Pharmaceuticals plc, and CAPNIA. Dr. Napchan and Dr. Crystal report no disclosures. Dr. Lipton serves/has served on scientific advisory boards for and received funding for travel from Bayer-Schering Pharma, Merck Serono, GlaxoSmithKline, Endo Pharmaceuticals, Kowa Pharmaceuticals America, Inc., Allergan, Inc., Neuralieve Inc., Ortho-McNeilJanssen Pharmaceuticals, Inc.; has served as a consultant for Advanced Bionics, AstraZeneca, Boehringer Ingelheim, Bristol-Myers Squibb, Cierra, Endo Pharmaceuticals, GlaxoSmithKline, Minster Pharmaceuticals plc, Merck Serono, Neuralieve, Inc., Novartis, and Ortho-McNeilJanssen Pharmaceuticals, Inc.; serves as Associate Editor of Cephalalgia and on the editorial boards of Neurology ${ }^{\circledR}$ and Headache; receives royalties from publishing Headache in Clinical Practice (Isis Medical Media, 2002), Headache in Primary Care (Isis Medical Media, 1999), Wolff's Headache (Oxford University Press, 2001, 2008), Managing Migraine: A Physician's Guide (BC Decker, 2008), and Managing Migraine: A Patient's Guide (BC Decker, 2008); has received speaker honoraria from the National Headache Foundation, the University of Oklahoma, the American Academy of Neurology, the Annenberg Foundation, Merck Serono, GlaxoSmith Kline, and Coherex Medical; receives research support from Allergan Inc., Ortho Ortho-McNeil-Janssen Pharmaceuticals, Inc., Minster Pharmaceuticals plc, Endo Pharmaceuticals, GlaxoSmithKline, Merck Serono, Neuralieve, Inc., ProEthics, the American Headache Society, National Headache Foundation, the Migraine Research Foundation, and the NIH [PO1AG03949 (Program Director, Project Leader), PO1AG027734 (Project Leader), RO1AG25119 (Co-I), K23AG030857 (Co-Mentor), K23NS05140901A1 (Co-Mentor), and K23NS47256 (Mentor)]; and holds stock options in Minster Pharmaceuticals plc and Neuralieve Inc.

Received October 13, 2009. Accepted in final form January 12, 2010.

\section{REFERENCES}

1. Petterson VH, Esmonde TF. Comparison of the handling of neurological outpatient referrals by general physicians and a neurologist. J Neurol Neurosurg Psychiatry 1993; 56:830.

2. Grande RB, Aaseth K, Lundqvist C, Russell MB. Prevalence of new daily persistent headache in the general population: The Akershus Study of Chronic Headache. Cephalalgia 2009;29:1149-1955.

3. Castillo J, Munoz P, Guitera V, et al. Kaplan Award 1998: Epidemiology of chronic daily headache in the general population. Headache 1999;39:190-196.

4. Bigal ME, Lipton RB, Tepper SJ, et al. Primary chronic daily headache and its subtypes in adolescents and adults. Neurology 2004;63:843-847.
5. Kung E, Tepper SJ, Rapoport AM, Sheftell FD, Bigal ME. New daily persistent headache in the paediatric population. Cephalagia 2009;29:17-22.

6. Vanast WJ. New daily persistent headaches: definition of a benign syndrome. Headache 1986;26:318.

7. Mack KJ. New daily persistent headache in children and adults. Curr Pain Headache Rep 2009;13:47-51.

8. Silberstein SD, Lipton RB, Solomon S, Mathew NT. Classification of daily and near-daily headaches: proposed revisions to the IHS criteria. Headache 1994;34:1-7.

9. The International Classification of Headache Disorders, 2nd edition. Cephalalgia 2004;24(suppl 1):9-160.

10. Li D, Rozen TD. The clinical characteristics of new daily persistent headache. Cephalalgia 2002;22:66-69.

11. Meineri P, Torre E, Rota E, Grasso E. New daily persistent headache: clinical and serological characteristics in a retrospective study. Neurol Sci 2004;25:S282-S282.

12. Lipton RB, Bigal ME, Ashina S, et al, American Migraine Prevalence and Prevention Advisory Group. Cutaneous allodynia in the migraine population. Ann Neurol 2008;63: $148-158$

13. Kroenke K, Spitzer RL, Williams JB. The PHQ-9: validity of a brief depression severity measure. J Gen Intern Med 2001;16:606-613.

14. Bigal ME, Tepper SJ, Sheftell FD, Rapoport AM, Lipton RB. Chronic daily headache: correlation between the 2004 and the 1988 International Headache Society diagnostic criteria. Headache 2004;44:684-691.

15. Olesen J, Bousser M, Diener $\mathrm{H}$, et al. New appendix criteria open for a broader concept of chronic migraine. Cephalalgia 2006;26:742-746.

16. Mack KG. What incites new daily persistent headache? Pediatr Neurol 2004;31:122-125.

17. Diaz-Mitoma F, Vanast WJ, Tyrrell DL. Increased frequency of Epstein-Barr virus excretion in patients with new daily persistent headaches. Lancet 1987;1:411-415.

18. Rozen T, Swidan SZ. Elevation of CSF tumor necrosis factor alpha levels in new daily persistent headache and treatment refractory chronic migraine. Headache 2007;47: 1050-1055.

19. Rozen TD, Roth JM, Denenberg N. Cervical joint hypermobility: a possible predisposing factor for new daily persistent headache. Cephalalgia 2006;26:1182-1185.

20. Donnet A, Levrier O. A consecutive series of ten cases of new daily persistent headache: clinical presentation and morphology of the venous system. Neurology 2009; 72(suppl 3):A419.

21. Goadsby PJ, Boes C. New daily persistent headache. J Neurol Neurosurg Psychiatry 2002;72(suppl 2):ii6-ii9.

22. Mokri B. Spontaneous low cerebrospinal pressure/volume headaches. Curr Neurol Neurosci Rep 2004;4:117-124.

23. Schievink WI. Misdiagnosis of spontaneous intracranial hypotension. Arch Neurol 2003;60:1713-1718.

24. Rasmussen BK, Olesen J. Migraine with aura and migraine without aura: an epidemiological study. Cephalalgia 1992; 12:221-228.

25. Agostoni E, Aliprandi A. The complications of migraine with aura. Neurol Sci 2006;27:S91-S95. 